\title{
ARCHAEAN EARTH
}

\section{Alkaline lakes of old}

Very few remnants of terrestrial surfaces from the Archaean eon are exposed at the Earth's surface today. But those traces that do remain suggest that Earth's early lands hosted areas of abundant microbial life. Some of the most visible and striking - remnants are found in the 2.7-billion-year-old Tumbiana Formation in Western Australia. These traces take the form of stromatolites and thrombolites, which were formed when microbial mats growing in lakes with minimal oxygen content grew on and around sediments.

The ratio of ${ }^{15} \mathrm{~N}$ to ${ }^{14} \mathrm{~N}$ recorded in the rocks of the Tumbiana Formation is unusually high. This signature could result from the nitrification of ammonium to $\mathrm{NO}^{2-}$ or $\mathrm{N}_{2} \mathrm{O}$, which then escaped from the system. However, a closer look at the isotopic composition of nitrogen in bulk samples and kerogens, alongside a comparison with the contemporaneous oceans, have led Eva Stüeken and colleagues to suggest that this nitrification process is not the whole story (Earth Planet. Sci. Lett. 411, 1-10; 2015).

The main additional process governing the unusual abundance of the heavier nitrogen isotope, they argue, is the volatilization and loss of ammonia. Volatilization of ammonia commonly occurs in modern alkaline lakes, but not in lakes with a more neutral $\mathrm{pH}$. There are indeed at least three lines of evidence to suggest that the Tumbiana lakes were alkaline. First, the lakes

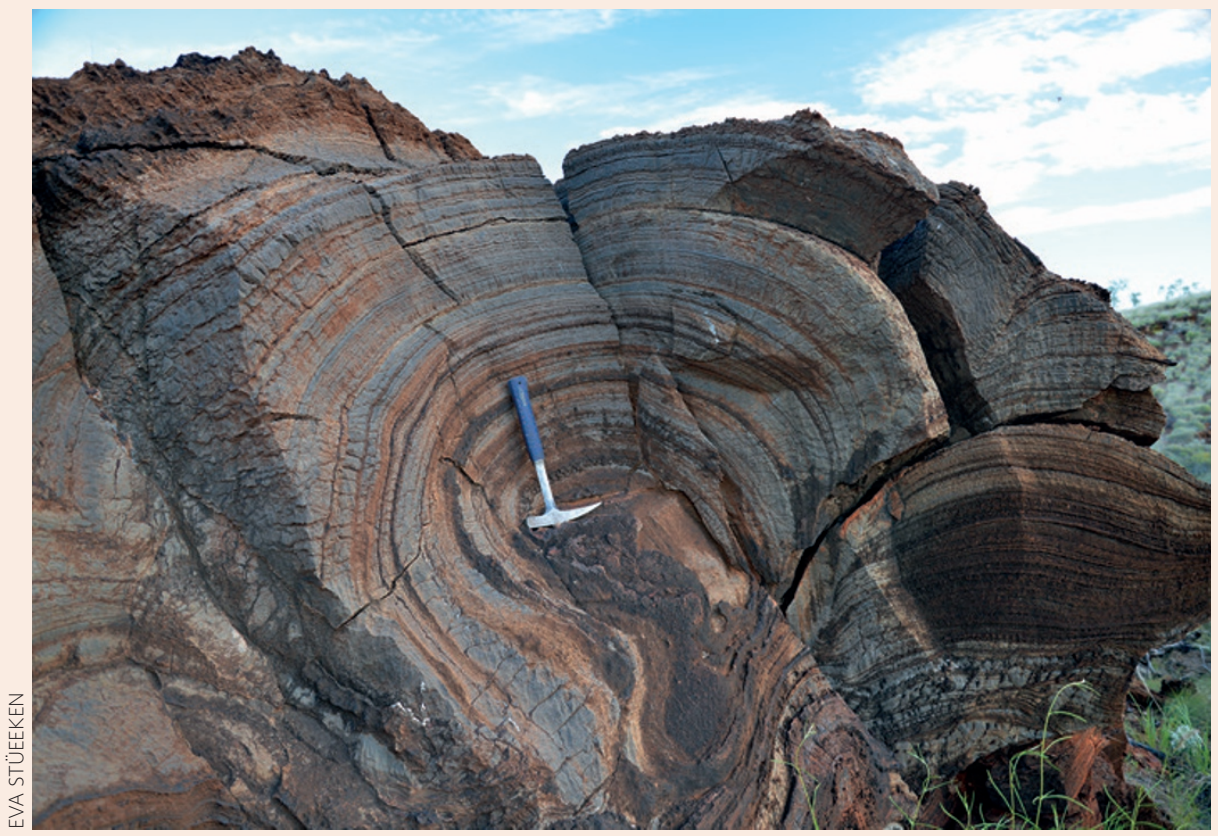

formed in fresh volcanic terrain and were frequently blanketed by volcanic ash a process known to increase alkalinity in modern settings. The lakes show features consistent with high rates of evaporation, such as desiccation cracks, which would also act to increase the lake $\mathrm{pH}$. And finally, the cyanobacteria living in the microbial mats that formed the stromatolites might have increased the lake's $\mathrm{pH}$ as they consumed $\mathrm{CO}_{2}$. All of these factors suggest that the lake's $\mathrm{pH}$ should have been at least 9, enough to trigger the release of ammonia.
Alkaline lakes today host diverse communities of cyanobacteria, which can locally raise oxygen contents in the lake waters. If alkaline lakes were a common feature of the Archaean Earth's surface, the cyanobacteria they hosted could have created hotspots of oxidative weathering. Such hotspots could explain why there is evidence for the oxidative weathering of elements like sulphur occurring long before oxygen finally accumulated in the atmosphere.

\section{ALICIA NEWTON}

